\title{
Aniracetam Reversed Learning and Memory Deficits Following Prenatal Ethanol Exposure by Modulating Functions of Synaptic AMPA Receptors
}

\author{
Julia Vaglenova*,', Noemi Pandiella', Nayana Wijayawardhane', Tiru Vaithianathan', Sandjay Birru', \\ Charles Breese', Vishnu Suppiramaniam' and Clark Randal' \\ 'Department of Pharmacal Sciences, Harrison School of Pharmacy, Auburn University, Auburn, AL, USA
}

\begin{abstract}
Specific pharmacological treatments are currently not available to address problems resulting from fetal ethanol exposure, described as Fetal Alcohol Syndrome or Fetal Alcohol Spectrum Disorders (FASD). The present study evaluated the therapeutic effects of aniracetam against cognitive deficits in a well-characterized and sensitive FASD Sprague-Dawley rat model. Ethanol, administered orally at a moderate dose $(4 \mathrm{~g} / \mathrm{kg} / 24 \mathrm{~h} ; 38 \% \mathrm{v} / \mathrm{v})$ during the entire course of pregnancy, caused severe cognitive deficits in offspring. Furthermore, both progeny genders were affected by a spectrum of behavioral abnormalities, such as a delay in the development of the righting reflex, poor novelty seeking behavior, and high anxiety levels in female rats. Cognitive disabilities, monitored in adult rats by a two-way active avoidance task, correlated well with a significant reduction of AMPA ( $\alpha$-amino-3 hydro- 5 methyl-isoxazole propionic acid) receptormediated miniature excitatory postsynaptic responses (mEPSCs) in the hippocampus. Administration of aniracetam for 10 days (postnatal days (PND) 18-27), at a dose of $50 \mathrm{mg} / \mathrm{kg}$ reversed cognitive deficits in both rat genders, indicated by a significant increase in the number of avoidances and the number of 'good learners'. After the termination of the nootropic treatment, a significant increase in both amplitude and frequency of AMPA receptor-mediated mEPSCs in hippocampal CA-I pyramidal cells was observed. Significant anxiolytic effects on PND 40 also preceded acquisition improvements in the avoidance task. This study provides evidence for the therapeutic potential of aniracetam in reversing cognitive deficits associated with FASD through positive post-natal modulation of AMPA receptors. Neuropsychopharmacology (2008) 33, I07I-1083; doi: I0.1038/sj.npp. I 301496; published online 4 July 2007
\end{abstract}

Keywords: prenatal ethanol; learning and memory; avoidance; anxiety; AMPA receptors; aniracetam

\section{INTRODUCTION}

It has been a challenge to identify the mechanisms underlying neurobehavioral abnormalities in the offspring of mothers who abuse alcohol during pregnancy. However, information obtained to date has not led to the establishment of specific pharmacological treatments to ameliorate or reverse defects resulting from fetal ethanol exposure, described as Fetal Alcohol Syndrome (FAS) (Jones et al, 1973) or Fetal Alcohol Spectrum Disorders (FASD) (Sokol et al, 2003; Hoyme et al, 2005; Chudley et al, 2005).

Human and animal studies (Maier and West, 2001; Irvine, 2003) have demonstrated that it is not the ethanol dose but the peak of blood alcohol concentration what is fundamental to the causing neurotoxic effects of ethanol on the developing CNS. Experimental models of FASD have shown cognitive deficits at all ages, from pre-weaning life through late adulthood (Barr et al, 2005). Deficits have been

\footnotetext{
*Correspondence: Dr J Vaglenova, Department of Pharmacal Sciences, Harrison School of Pharmacy, Auburn University, Auburn, AL 36849, USA, Tel: + | 33484483 67, Fax: + | 334844 8331,

E-mail: vagleju@auburn.edu

Received 6 December 2006; revised 21 May 2007; accepted 29 May 2007
}

observed in a wide variety of learning and memory tasks, including spatial reference memory (Gabriel et al, 2005; Kim et al, 1997; Matthews and Simson, 1998; Zimmerberg and Weston, 2002), working memory (Neese et al, 2004), and associative memory (Clausing et al, 1995; Vaglenova, 1992; Vaglenova and Petkov, 1998, 2001; Weeber et al, 2001).

The process of cognition is complex and involves many brain systems. Increasing evidence indicates that the hippocampus (Allan et al, 1998; Zola-Morgan and Squire, 1986) and the glutamate neurotransmitter system (Morris et al, 1986; Morris, 1989) are important for the process of memory formation. The fast glutamatergic neurotransmission in the mammalian brain is mediated mainly via AMPA ( $\alpha$-amino-3 hydro-5 methyl-isoxazole propionic acid) receptors, and their regulated activity is critical for normal synaptic transmission and specialized cognitive functions. The impairment of AMPA receptor-mediated glutamatergic transmission can result in cognitive deficits (Reisel et al, 2002), and the hippocampal AMPA receptor activation is necessary for the process of memory consolidation and retention (Yoshihara and Ichitani, 2004).

Currently, there are no effective pharmacological agents available for improving complex behavioral abnormalities 
resulting from prenatal alcohol exposure. The CNS stimulants methylphenidate (Ritalin), $d$-amphetamine (Dexedrine), premoline (Cylert) and in rare cases caffeine have shown a degree of efficacy in treating attention disorders and hyperactivity in children with FAS (Snyder et al, 1997; Riley et al, 2001, 2003). However, children with FAS have disturbances in the brain neurochemistry or even in brain structures, so their responses to standard psychostimulant medication can be quite unpredictable (O'Malley and Nanson, 2002). Recent experimental data suggest that early dietary intervention by choline supplementation may reduce the severity of FASD (Thomas et al, 2000). A fragment of the glial-derived activity-dependent neuroprotective protein NAP has been shown to act against alcohol-induced embryo toxicity and growth retardation in mice (Spong et al, 2001). Aniracetam, a 2-pyrrolidinone derivate [1-(4-methoxybenzoyl)-2-pyrrolidinone], among other compounds, has been categorized as a piracetam analog (Gouliaev and Senning, 1994) and has minimal side effects (Foltyn et al, 1983; Gouliaev and Senning, 1994) with LD 50 around $5.0 \mathrm{~g}$ for rats and mice; for an $80 \mathrm{~kg}$ human, this dosage would equate to 500 times the standard dose of $1.5 \mathrm{~g}$. No toxic or teratogenic effects have been found. Aniracetam has been used in clinical practice and is usually prescribed in Europe to treat brain disturbances and intellectual disorders caused by alcohol, tranquilizers, neuroleptics, depressants, barbiturates, and agents impairing circulation in the brain (Gouliaev and Senning, 1994; Shorvon, 2001). The US aniracetam patent holder, HoffmanLaRoche, has had problems gaining FDA approval for treating Alzheimer's disease.

At the molecular level, aniracetam is an allosteric modulator of the AMPA type of glutamate receptors (Ito et al, 1990; Black, 2005), slowing the deactivation and desensitization of these receptors by stabilizing the glutamate bound conformation (Jin et al, 2005). Thus, the measurement of AMPA receptor-mediated synaptic currents in the hippocampal pyramidal cells of rats with cognitive deficits following both prenatal ethanol exposure and post-natal aniracetam treatment helped to establish the synaptic mechanism of memory improvement by aniracetam. Therefore, we hypothesize that learning and memory deficits following prenatal ethanol exposure can be restored by modulation of glutamatergic synaptic transmission.

CNS damage of offspring used in this study was caused only in utero, in a period that approximates the first and second trimester of human pregnancy (Olney, 2002, 2004). A previous model has shown that similar deficits resulted from ethanol exposure during entire course of pregnancy and lactation (Vaglenova and Petkov 1998, 2001). In the present study, aniracetam was administered before adolescence and cognitive parameters were investigated 1 month later in adult offspring. The functional properties of synaptic AMPA receptors were monitored after the termination of aniracetam administration. We also compared gender differences when observing the effects of aniracetam treatment on offspring with moderate prenatal ethanol exposure. The aim of this study was to develop a therapeutic protocol for attenuating cognitive deficiencies in a rat offspring model when ethanol was administered at a moderate dose once per day during the entire course of pregnancy.

\section{RESEARCH DESIGN AND METHODS}

\section{Subjects, Treatment Groups, and Drugs Administration}

Pregnant Sprague-Dawley rats $(n=24)$ from Zivic-Miller Laboratories (Pittsburgh, PA) were divided into two groups and treated with ethanol at a single moderate dose $(4 \mathrm{~g} / \mathrm{kg} /$ day; $38 \mathrm{v} / \mathrm{v} \%)$ or sucrose (equicaloric to ethanol) from gestation day (GD) 3 throughout pregnancy. The ethanol concentration permitted avoiding the stress effects of repeated intragastric intubation (Keshavarzian et al, 2001) and withdrawal episodes (Maier and West, 2001).

The day after parturition was considered post-natal day (PND) 1 and litters were culled to an equal number of males and females whenever possible, with an equal number of 10 pups per mother. The progeny were weaned on PND 25, and to control litter effects, not more than 1 mate per gender was placed into a particular group (Wainwright, 1998). The colony room was maintained at $22-24^{\circ} \mathrm{C}$ and kept under a $12 \mathrm{~h}$ light/dark cycle.

Twenty animals per group are required to detect a $20 \%$ difference between treatment groups (Vaglenova et al, 2004). A total number of 240 pups were grouped in four treatment groups: ethanol (E), sucrose (C), ethanolaniracetam (E-A), and sucrose-aniracetam (C-A). Active avoidance, plus-maze, locomotor activity, and developmental milestones measures were assessed for each group $(n=20 /$ sex $)$ of pups and each animal was with an own identical number. An additional 10 pups per group were used for electrophysiological studies.

Aniracetam (Ampamet) at a dose of $50 \mathrm{mg} / \mathrm{kg}$, dissolved in distilled water $(2 \mathrm{ml} / \mathrm{kg})$ was intubated by gavage in animals from the ethanol (E-A) and sucrose (C-A) groups for 10 days during the pre-adolescent (PND 18-27) period (Spear, 2000). The E and C groups also were exposed to a gavage procedure for 10 days, receiving the same amount of distilled water instead of aniracetam solution. The maximum benefit of the dose of $50 \mathrm{mg} / \mathrm{kg}$, the duration, and the route of administration (the agent is orally active) were determinated in accordance with previous investigations in our laboratory over the past 20 years and supported by numerous other authors (Coper and Herrman, 1988; Giurgea, 1980; Gouliaev and Senning, 1994; Petkov et al, 1991; Vaglenova and Petkov, 2001; Voronina, 1989).

\section{Behavioral and Developmental Analysis}

Developmental analysis. After birth, animals from the ethanol and sucrose groups were observed for mortality rates, body weights, incisor eruption, and eye opening. Righting reflex and negative geotaxis were performed from the third day of age and continued until all tested animals in the various treatment groups met the criteria (see Scheme). Righting reflex was tested by placing the animal on its back, with the time required to return to all four paws recorded. Negative geotaxis was measured by observing the time required for each animal to fully turn and face upwards when placed with its head facing down on a $30^{\circ}$-inclined carpeted platform. All control animals achieved the criteria of performing the test in $45 \mathrm{~s}$ after 6 days of the trial (Bonthius and West, 1988). 
Exploratory activity and novelty-seeking behavior. On PND 18 (see Scheme), the pups used in developmental milestone measures were assessed for exploration in an open field and 'hole' board activity plexiglas chamber $(46 \times 46 \mathrm{~cm})$ with five holes $(3 \mathrm{~cm}$ diameter) located on the floor. A computer-controlled photo beam activity system (Omithech Electronics Inc., Columbus, $\mathrm{OH}$ ) counted the pups' horizontal and vertical movements, the total distance of movements, rest time, time spent in corners, and number of head dips (Palanza et al, 2001; Vaglenova et al, 2004) in the course of a $10 \mathrm{~min}$ trial. The trial was performed between 0900 and 1100 hours in a soundproof room.

Plus maze activity. At the age of 40 days, all four groups (C, $\mathrm{E}, \mathrm{C}+\mathrm{A}, \mathrm{E}+\mathrm{A}$ ) were assessed for anxiety by spending $5 \mathrm{~min}$ in an elevated plus-maze (see Scheme). The black plexiglas apparatus was elevated $50 \mathrm{~cm}$ above the floor and constructed in a 'plus' shape with two open arms $(50 \times 10 \mathrm{~cm})$ and two arms enclosed by $30 \mathrm{~cm}$ high walls. The four opposing arms connected by $10 \times 10 \mathrm{~cm}$ square area in the center. To start the trial, each rat was placed in the center of the maze, facing an open arm. The trials were videotaped and number of seconds spent in each arm was recorded. The number of pups' entering into each arm also was recorded (Escorihuela et al, 1995; Vaglenova et al, 2004).

Two-way active avoidance (shuttle-box). The same four groups of rats were assessed for learning and memory at the age of 60 days. A repeated training procedure, called the shuttle-box active avoidance test, was used (Vaglenova and Petkov, 1998, 2001; Vaglenova et al, 2004) (see Scheme). A computer controlled the apparatus (Columbus Instruments), which consisted of two compartments, each $(47.5 \times 27 \times$ $22.5 \mathrm{~cm}$ ) connected by an opening at the center. The condition stimulus consisted of a tone $(80 \mathrm{~dB})$ and light $(5 \mathrm{~W})$, activated for $5 \mathrm{~s}$ at the same time, alternatively in each compartment when the rat could avoid the unconditioned stimulus (US) by passing into the adjoining compartment. The US was a foot shock of $10 \mathrm{~s}$, caused by an electric current (0.5-0.7 mA, ac), and delivered trough the grid floor of the apparatus. The strength of the electricity was dependent on the animal's body weight and usually was lower for females. US could be escaped passing into the next compartment. The intertrial interval was $15 \mathrm{~s}$, and each rat was trained for 5 consecutive days with 30 trials in each session. The retention test was performed 7 days after the last training day and showed the level of long term memory (Heise, 1984; Yonkov et al, 1989; Vaglenova et al, 2004).

\section{Hippocampal Slice Preparation and Electrophysiology}

AMPA receptor-mediated miniature excitatory postsynaptic currents (mEPSCs) were investigated using the whole-cell patch clamp technique. The technique described below provided an opportunity to test the variations in AMPARmediated synaptic transmission in the treatment groups. To minimize the stress and acute effect of aniracetam, animals were given at least 1 day resting before decapitation. Rats were sedated with $\mathrm{CO}_{2}$ and decapitated, and a vibratone (Warner instruments, Hamden, CT) was used to prepare transverse hippocampal slices of $400 \mu \mathrm{m}$ thickness in ice- cold, pregassed $\left(95 \% \mathrm{O}_{2} / 5 \% \mathrm{CO}_{2}\right)$ ACSF containing (in $\mathrm{mM}$ ) $\mathrm{NaCl} 119, \mathrm{KCl} 2.5, \mathrm{MgSO}_{4}$ 1.3, $\mathrm{CaCl}_{2}$ 2.5, $\mathrm{NaH}_{2} \mathrm{PO}_{4}$ 1.0, $\mathrm{NaHCO}_{3}$ 26.0, and dextrose 11.0. Slices were maintained for $\geqslant 1 \mathrm{~h}$ in gassed ACSF and then transferred to a chamber perfused with ACSF at a rate of $2 \mathrm{ml} / \mathrm{min}$. Slices were visualized with Nomarski differential interference contrast optics using an Olympus BX51WI (Olympus, USA) equipped with a water immersion lens. In the presence of channel blockers $(1 \mu \mathrm{M}$ TTX, $100 \mu \mathrm{M}$ APV, and $50 \mu \mathrm{M}$ picrotoxin), we recorded the AMPAR-mediated, action potential independent mEPSCs in CA1 pyramidal neurons, using whole-cell configuration as described previously (Zeng and Tietz, 1999). At the end of each experiment, $30 \mu \mathrm{M}$ CNQX was added to block AMPA currents. Recordings were made with a patch pipette (5-7 M $\Omega$ ) filled with a solution containing (in $\mathrm{mM}$ ): K-gluconate 100, EGTA 0.6, $\mathrm{MgCl}_{2}$ 5.0, Na-ATP 2.0, Na-GTP 0.3, and HEPES 40. Neurons were voltage-clamped $\left(V_{\mathrm{h}}=-80 \mathrm{mV}\right)$ in continuous mode (cSEVC) using an Axopatch 200 B amplifier (Axon Instruments Inc., Foster City, CA). Current output was low-pass filtered $(2 \mathrm{kHz})$, DC-offset, and amplified 10000 -fold. The signal was continuously monitored on-line (pClamp 8 Software, Molecular Devices Corp., Sunnyvale, CA), digitized (Digidata 1200, Axon), and stored in computer disks for offline analysis. Baseline mEPSC activity was recorded in each neuron for at least $5 \mathrm{~min}$.

\section{Data Analysis}

Prenatal and post-natal treatment and gender were considered as factors when analyzing exploratory activity, anxiety test, avoidance test $(2 \times 2 \times 2)$, and electrophysiological measures using ANOVA. Training days were presented as a within factor (when appropriate). Specific contrast was investigated by Bonferroni post hoc analysis to identify the source of the variance, with $P \leqslant 0.05$ considered significant. The rats in each treatment group also were stratified into 'helpless', 'poor', and 'good' learners, which allowed a qualitative measure of performance (Vaglenova et al, 2004). 'Good' learners were defined as animals that performed at or above the control group mean and showed an increasing number of avoidances during the last 2 days of the test, in contrast to 'poor learners', which exhibited a decreasing number of avoidances. 'Helpless' rats were completely unable to perform the task, displaying one or less avoidances during each trial (Vaglenova and Petkov, 2001; Vaglenova et al, 2004). Both the stratification of the learners and developmental reflexes were analyzed using $\chi^{2}$ to examine changes between treatment groups and gender.

Electrophysiologically recorded events were detected and averaged using the Mini Analysis Program (Synaptosoft Inc., Leonia, NJ). Peak mEPSC amplitudes were measured from the baseline.

\section{RESULTS}

\section{Mortality and Body Weight in Rats Exposed Prenatally to Ethanol}

The ethanol dose and gavage procedure used in these studies did not adversely affect overall dietary consumption in the ethanol-treated mothers. No differences were 
observed in their body weights during gestation or lactation as compared with the sucrose-treated control animals. Blood ethanol levels $40 \mathrm{~min}$ after gavaging on GD 14 were $184.0 \pm 0.3 \mathrm{mg} / \mathrm{dl}$. No birth defects, stillborn pups, maternal cannibalism, or significant post-natal mortality rate were detected in any of the experimental groups. However, birth body weights of offspring in ethanol groups were significantly reduced compared with controls, and they failed to recover until PND 5 (not shown).

\section{Developmental Tasks}

$\chi^{2}$ Analysis indicated significant deficits in the righting reflex of prenatally E-treated pups when compared with sucrose-control animals $\left(\chi^{2}=66.0 ; P<0.001\right)$ (Figure 1). All animals in the control groups reached criteria ( $>90 \%$ of the animals performing the righting reflex in under $2 \mathrm{~s}$ ) within 5 days, compared with 8 days for the ethanol-treated. Latencies to righting were also statistically higher compared with controls $(p<0.05)$ (not shown). No gender differences in the task performance $(p>0.05)$ were observed. All control animals achieved the criteria of $45 \mathrm{~s}$ on the negative geotaxis task after 5 days of trials. Pups in prenatally E-treated groups reached the criteria after 6 days of the trials, and no significant difference with controls in performance of the task was detected.

Behavioral tasks. Several behavioral parameters were investigated at different post-natal developmental periods, ranging from spontaneous locomotor activity and noveltyseeking behavior in pre-weanling animals on PNDs 18 and 25 to anxiety in adolescence (PND 40) and cognitive abilities in adulthood (PND 60-72). These experiments are summarized below (see Scheme).

\section{Exploratory Activity and Environmental Adaptation}

Significant abnormalities in locomotor activity were not evident either in 18- or in 25-day-old E-exposed rats (not shown). As shown in Figure 2, hole-board exploratory activity, as defined as the number of head-dips into the holes located on the floor, was significantly reduced in both genders of 18-day-old E-treated offspring compared with sucrose-treated controls (treatment $\mathrm{F}_{(1,79)}=5.05 ; P<0.05$ ). For this task, all animal activity was mostly during the first $5 \mathrm{~min}$ of the trial, with significant habituation to the environment, demonstrated during the last $5 \mathrm{~min}$ (treatment/periods $\left.\mathrm{F}_{(1,79)}=5.01 ; p<0.02\right)$. These results could be

Scheme

Pregnancy

Rat Offspring

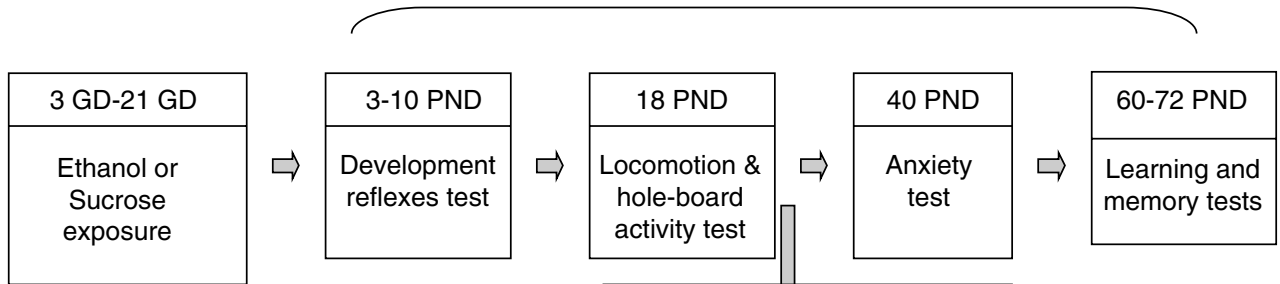

18-27 PND aniracetam treatment

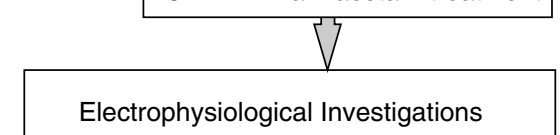

Righting Reflexes in Males

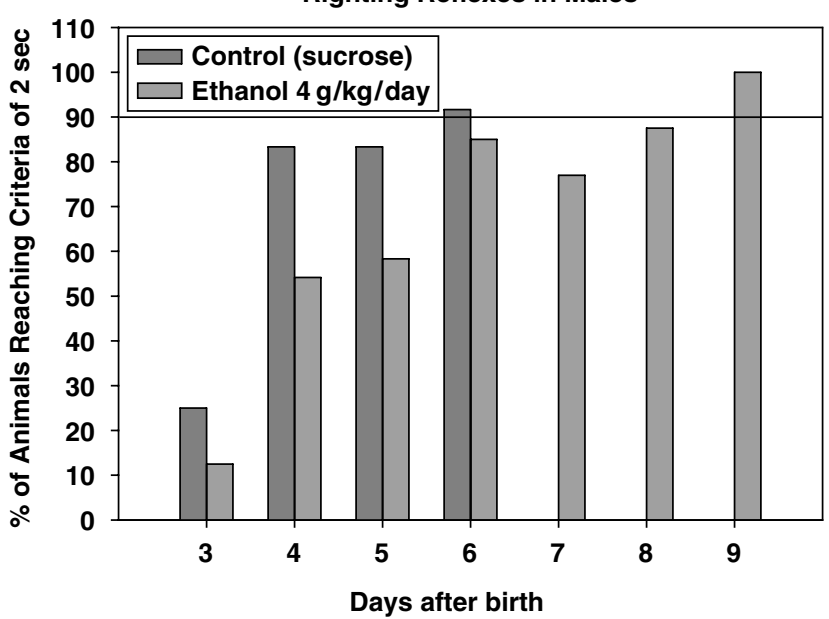

Righting Reflexes in Females

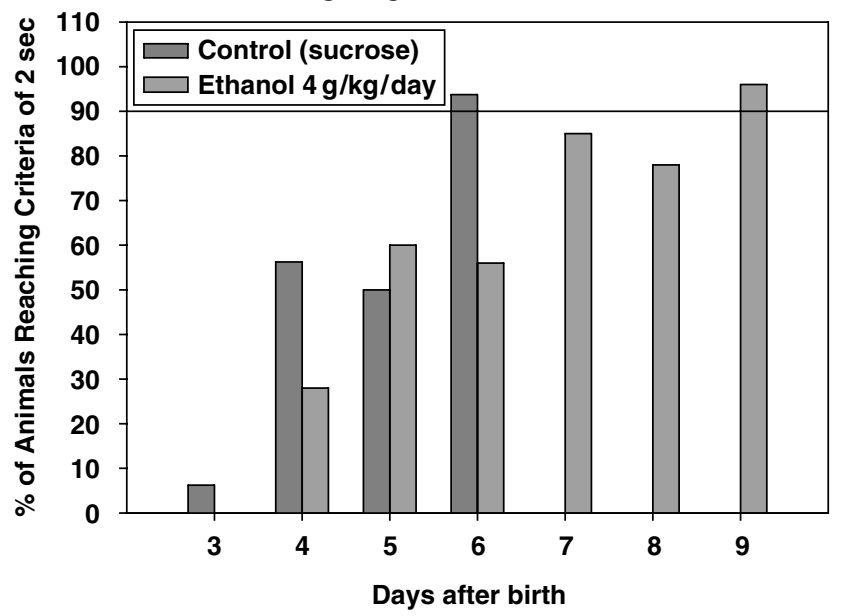

Figure I Percentage of male and female pups, prenatally exposed to ethanol or sucrose, (ordinate) eliciting a fully righting reflex as a function of age in days (abscise). Differences between control and ethanol groups were investigated by $\chi^{2}$, taking into account sex and treatment. $\chi^{2}=66.0$ with 24 degree of freedom; $(P<0.001)$. 
interpreted as decreased novelty seeking activity, poor adaptation, and neophobia in ethanol exposed animals.

\section{Effects of Aniracetam on Anxiety in the Elevated Plus Maze Test}

The plus maze is based on the rodent's natural aversion to being exposed to an elevated space, and serves as a generalized test of anxiety levels. These levels were assessed by measuring the number of entries onto and the length of time spent in the open arm of the maze, or the 'aversive area.' Forty-day-old rats were tested because the adolescent rat is especially vulnerable to anxiety and stress, possibly due to the immaturity of brain mechanisms involved in the regulation of anxiety (Doremus et al, 2004; Vaglenova et al, 2004). As seen in Table 1, only the ethanol-exposed female offspring spent significantly less time in the unprotected arms, revealing an increase in anxiety. Statistical comparison analysis, using prenatal exposure and post-natal treatment design, demonstrated a primary effect of postnatal aniracetam treatment for the number of entries into the open arms for both genders (males: $\mathrm{F}_{(1,84)}=31.0$, $p<0.0001$; females: $\left.\mathrm{F}_{(1,84)}=62.6, p<0.0001\right)$, which is indicative of aniracetam's strong anxiolytic effect. There

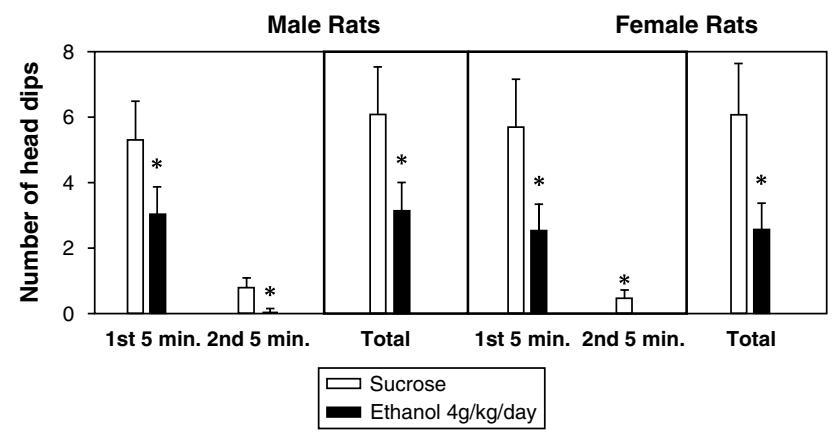

Figure 2 The mean $( \pm S E M)$ number of head dips made by rats exposed prenatally to ethanol $(4 \mathrm{~g} / \mathrm{kg} / 24 \mathrm{~h} ; \mathrm{v} / \mathrm{v} 38 \%)$ and sucrose on a hole board apparatus at 18 days of age during 10 min session statistically analyzed by ANOVA. Treatment and sex were considered as factors. Ethanol exposed rats of both genders (40 days old) significantly made few numbers of head dips (treatment $F_{(1.79)}=7.49 ; p=0.007$ ) when compared with controls (sucrose treated). ${ }^{*} P<0.05$ ethanol vs sucrose. was no effect of treatment or interactions for entries with prenatal drug exposure (all $p>0.05$ ). In contrast, primary effects of post-natal aniracetam treatment were observed for the time spent in the open arms for both genders (male: $F_{(1}$, ${ }_{84)}=15.5, p<0.0003$; female: $\left.\mathrm{F}_{(1,84)}=31.6, p<0.0001\right)$, also indicative of the anxiolytic effect of aniracetam; however, there was a strong interaction for time in the open arms with prenatal drug exposure and aniracetam treatment in both genders, with the main effect detected being a further improvement as a result of aniracetam treatment in the ethanol-exposed offspring as compared with controls (interaction prenatal drug exposure $\times$ post-natal aniracetam treatment, males: $\mathrm{F}_{(1,84)}=5.6, p<0.03$; female: $\mathrm{F}_{(1,84)}=4.1$, $p<0.05)$.

\section{Effects of Prenatal Ethanol Exposure on Learning and Memory of 60-Day-Old Rats}

As shown in Figure 3, rats of both genders exposed to ethanol during pregnancy displayed significantly fewer avoidances during the training and retention tests at 60 days of age (male: $F_{(1,250)}=13.6, p=0.003$; female: $F_{(1}$, $263)=14.0, p=0.0002)$. These changes are a result of an increase in the number of animals classified as 'poor' or 'helpless' learners in both genders (Figure 4). It is interesting to note that there was a specific gender effect, seen in the higher percentage of 'helpless' male learners in the ethanol exposed offspring as compared with females, whereas less than $10 \%$ of both controls were considered 'helpless.' Surprisingly, $25 \%$ of ethanol-exposed males and $20 \%$ of ethanol-exposed females were not affected by ethanol exposure, demonstrating a high number of avoidances and qualifying as 'good learners.' This result corresponds to human outcomes, which showed that alcoholic mothers do at times give birth to otherwise healthy children. By contrast, however, more than $50 \%$ of control animals of either gender were considered as 'good learners.'

\section{Effects of Aniracetam on Learning and Memory Ability of 60 Days-Old Rats Prenatally Exposed to Ethanol}

As shown in Figures 3 and 4, cognitive function in both genders exposed to ethanol significantly improved with aniracetam administration. The primary effects of post-

Table I Changes of Number of Entries and Time in Seconds Spend in the Open Arms during the Elevated Plus-Maze's Test

\begin{tabular}{|c|c|c|c|c|}
\hline Sucrose & & Ethanol $4 \mathrm{mg} / \mathrm{kg} / \mathrm{day}$ & Sucrose+Aniracetam $50 \mathrm{mg} / \mathrm{kg} / \mathrm{day}$ & Ethanol+Aniracetam \\
\hline Number of entries into open arms & $2.5 \pm 0.3$ & $2.4 \pm 0.3$ & $4.6 \pm 0.7^{*}, \#$ & $5.5 \pm 0.6^{*, \#}$ \\
\hline Female & $n=19$ & $n=29$ & $n=17$ & $n=17$ \\
\hline
\end{tabular}

Values are expressed as the mean \pm SEM.

$* P<0.000$ I compared with control.

${ }^{\#} P<0.00$ I compared with ethanol-treated rats. 

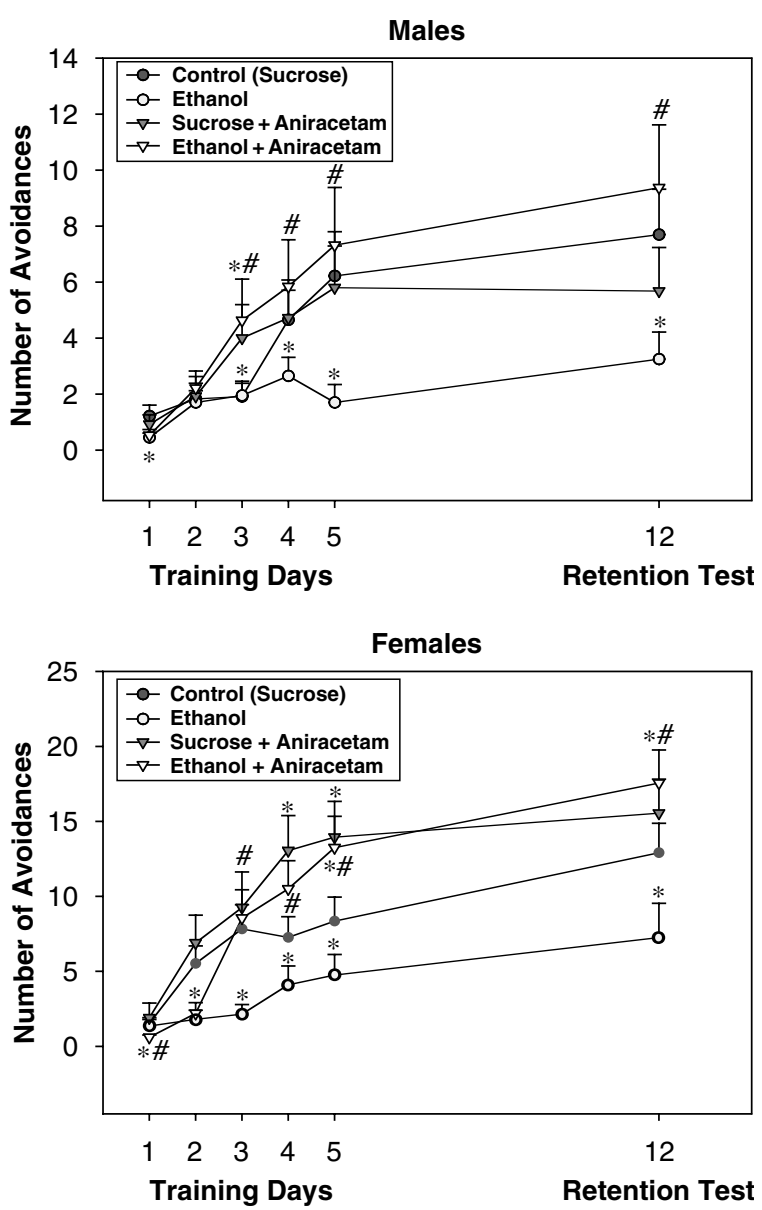

Figure 3 Effects of prenatal ethanol exposure ( $4 \mathrm{~g} / \mathrm{kg} /$ day; $38 \mathrm{v} / \mathrm{w} \%)$ and 10 days (PND 18-27) post-natal aniracetam $(50 \mathrm{mg} / \mathrm{kg} /$ day) treatment on the active avoidance task's performance of 60-day-old rats. Top: the mean number of avoidances made each day over a 5-day training period and on the day 12 after the training session by male (top) or female rats (bottom) $(n=20 /$ sex $)$. Values are expressed as the mean \pm SEM. $* P<0.000$ I compared with control. ${ }^{\#} P<0.05$ compared with ethanol treated rats.

natal aniracetam treatment were observed for acquisition and retention in females $\left(\mathrm{F}_{(1,240)}=14,1 ; p<0.002\right)$ but not in males $\left(\mathrm{F}_{(1,230)}=0.12, p=0.7\right.$.) However, there was a strong interaction between the number of avoidances with prenatal drug exposure and aniracetam treatment in both genders, with the simple main effect indicating improvement as a result of aniracetam treatment in the ethanolexposed offspring as compared with controls (interaction prenatal drug exposure $\times$ post-natal aniracetam treatment, males: $\mathrm{F}_{(1,473)}=6.5, p=0.01$; female: $\mathrm{F}_{(1,}$ 502) $=43.3$, $p<0.0001)$.

As heterogeneity in learning and memory responses is typical for both humans and experimental animals, the stratification of learners is an innovative method that offers an opportunity to use optimal performance parameters as a useful tool to assess the efficacy of different drugs in modifying cognitive function. This method takes into account how many animals could accurately perform the complex task, instead of simply examining the mean performance of the group, and also takes into account how the number changes as a result of drug administration. Further analysis based on the stratification of rats as

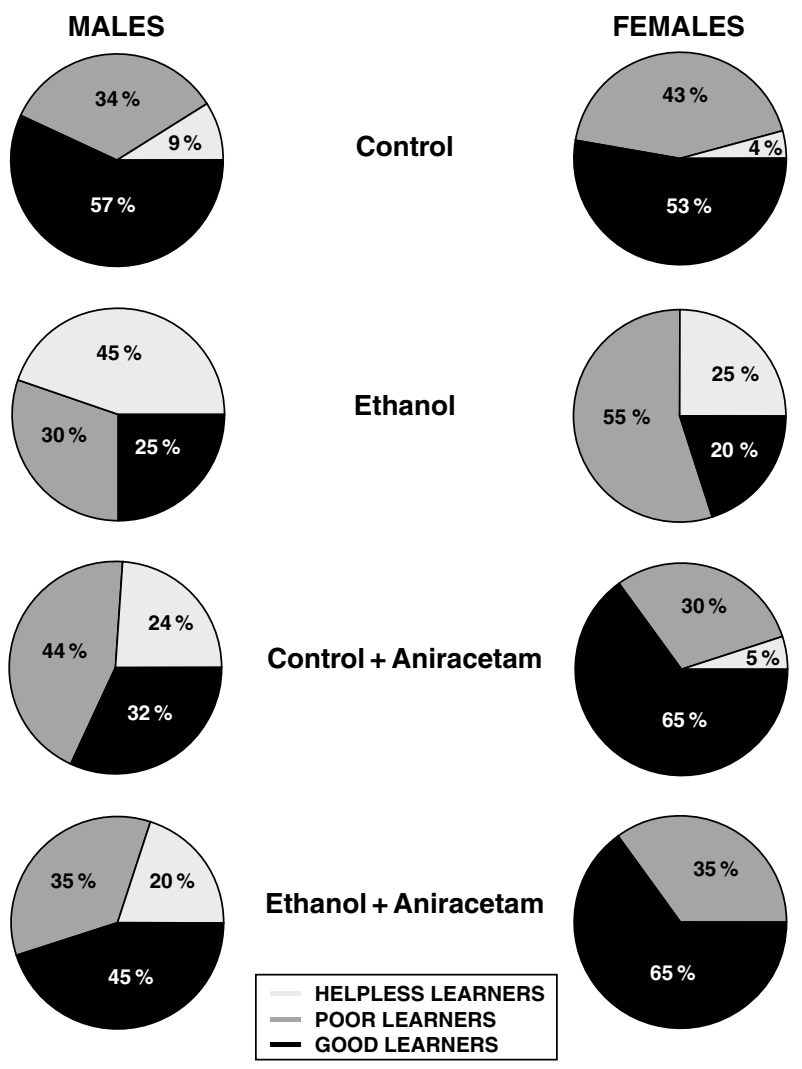

Figure 4 Stratification of helpless, poor, and good learners among rats prenatally exposed to ethanol $(4 \mathrm{~g} / \mathrm{kg} ; 38 \mathrm{v} / \mathrm{v} \% /$ day $)$, sucrose, or aniracetam. Aniracetam $(50 \mathrm{mg} / \mathrm{kg}$ ) was administered for 10 days during the preadolescent period (PND 18-27) on rats exposed to ethanol or sucrose prenatally. $(n=20 /$ sex $)$. Significance by $\chi^{2}$ males $=45.89$; $P<0.00$ I; females $=79.84 ; P<0.00$ I compared by controls.

learners gave other interesting information. As shown in Figure 4, the recovery after aniracetam therapy in females was more complete, because their learning indicators (number of avoidances and number of 'good learners') significantly outnumbered even those of the control group $\left(\chi^{2}=8.0 ; P<0.001\right)$. The number of 'helpless' learners in the aniracetam-treated groups was significantly lower than in the group treated only with ethanol. Surprisingly, their number as well as the number of 'poor learners' was higher in aniracetam-treated males $(\mathrm{C}+\mathrm{A})$ compared with controls (C) $\left(\chi^{2}=31.17 ; P<0.001\right)$, although there were no differences between 'mean' avoidances, further supporting the improvement in ethanol-exposed offspring as a result of aniracetam treatment.

In an attempt to understand the difference between the male and female groups after aniracetam administration, we further examined various parameters associated with the performance of the active avoidance task. Analysis of the frequency of escape failures (EFs) revealed acquisition problems in all male groups $\left(\chi^{2}\right.$ males/females $=19.0$; $p<0.02$ ) (Figure 5). EFs were used as a measure of the rat's inability to overcome the stress and anxiety associated with the US or electrical shock (Ferguson et al, 2000). As shown in Table 2, the majority of escape failures were displayed by rats within the 'helpless' groups, although there was a significant difference in their numbers in both 

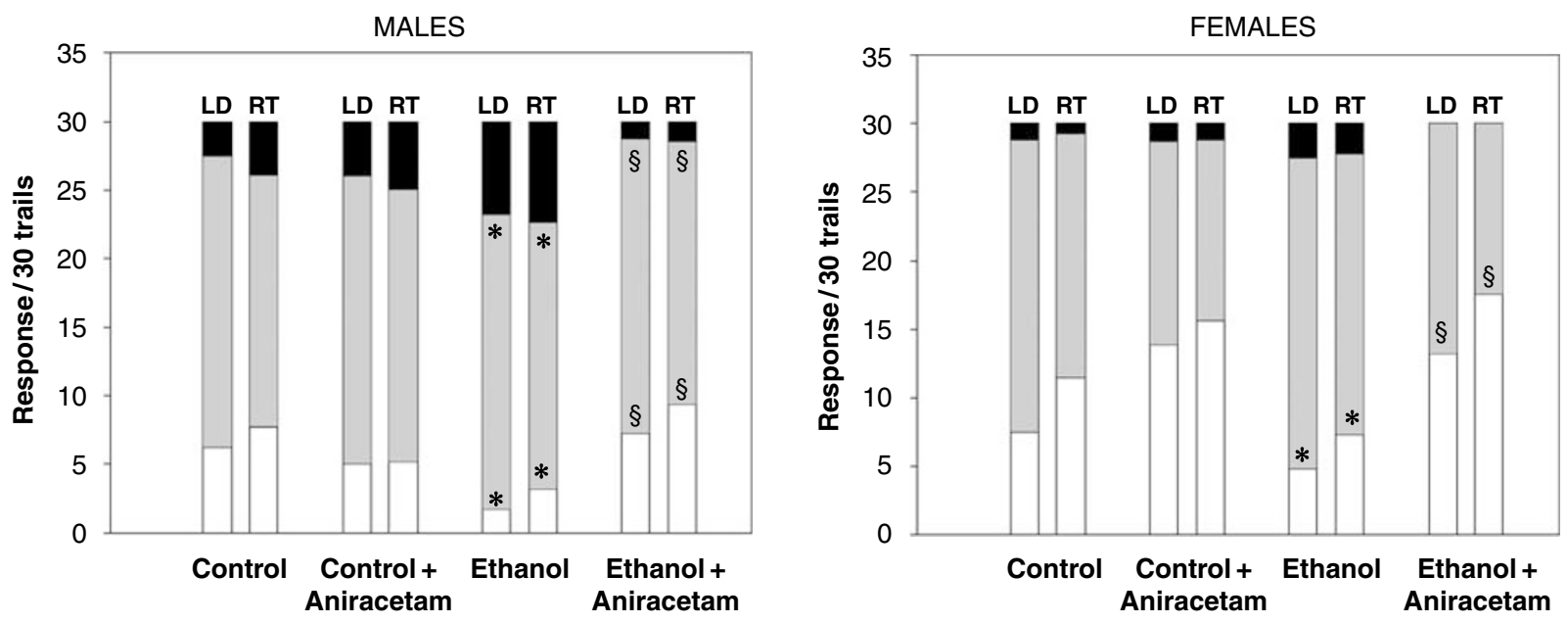

\section{Avoidances \\ Escapes \\ Escape Failures}

Figure 5 Effects of prenatal ethanol ( $4 \mathrm{~g} / \mathrm{kg} /$ day; $38 \mathrm{v} / \mathrm{v} \%$ ) or sucrose exposure, and postnatal aniracetam $(50 \mathrm{mg} / \mathrm{kg})$ on avoidances, escape failures and escapes in an active avoidance task. Aniracetam was administered for 10 days during the pre-adolescent period ( $18-27)$ in rats exposed prenatally to ethanol or sucrose $(n=20 /$ sex $): * P<0.0$ I compare to controls. ${ }^{\circledR} P<0.0$ I compare to ethanol group.

Table 2 Changes in Percentage of Helpless Learners and Rats with $>15$ Escape Failures during Active Avoidance Test in Shuttle Box

\begin{tabular}{llcc}
\hline Treatment groups & $\begin{array}{l}\text { Gender } \\
\mathbf{N = 2 0}\end{array}$ & $\begin{array}{c}\text { Helpless } \\
\text { Learners }\end{array}$ & $\begin{array}{l}\text { Percent of rats } \\
\text { with }>\text { I5 EFs }\end{array}$ \\
\hline Ethanol & Males (20) & 45 & 45 \\
& Females (20) & 25 & 10 \\
Sucrose & Males (20) & 9 & 9 \\
Sucrose+Aniracetam & Females (20) & 4 & 4 \\
\multirow{2}{*}{ Ethanol+Aniracetam } & Males (20) & 24 & 24 \\
& Females (20) & 5 & 5 \\
& Males (20) & 20 & 5 \\
\hline
\end{tabular}

genders. Nevertheless, no difference was detected between control and control-aniracetam-treated animals $(P=0.28)$. A dramatic increase in the number of EFs was observed in male ethanol-treated animals, which corresponded to the increase in the number of 'helpless' learners in this group (Table 2 and Figure 4 ).

The large decrease in escape latency and escape failures in male ethanol-aniracetam-treated animals coincided with an increase in their learning and memory performance, indicating that the decreased performance in ethanoltreated rats may have resulted in part from increased stress and anxiety in the 'poor' and 'helpless' learners of both genders. By contrast, the larger number of helpless animals in the female ethanol-treated group corresponded to the negligible number of rats with $>15 \quad \mathrm{EFs} \quad\left(\chi^{2}=3.89\right.$; $P=0.28$. Aniracetam was able to improve disrupted fixed-interval performance in ethanol-exposed rats in both genders, as seen by the elimination of escape failures during the last learning and retention phases of the experiment (treatment $\mathrm{F}_{(3,316)}=11.0 ; p<0.0001$ ), thereby significantly increasing the number of good learners (Figure 4).

\section{Effects of Prenatal Ethanol Exposure and Chronic Preadolescent Aniracetam Treatment on AMPA Receptor-Mediated Synaptic Transmission}

To establish whether modifications in AMPAR-mediated synaptic transmission contributed to the observed learning and memory deficits caused by chronic prenatal ethanol exposure, measurements of mEPSCs were carried out in the hippocampal CA1 area of offspring. We compared the frequency and mean amplitude of mEPSCs, which correspond to a single quantum of transmitter release from individual synapses (Hsia et al, 1998). As mEPSCs are primarily elicited by a single vesicle release, analysis of mEPSCs may help to discriminate between pre- and postsynaptic modifications associated with ethanol exposure. Changes in the frequency of miniature currents indicate alterations in presynaptic mechanisms (transmitter release probability, number of active zones, and vesicles immediately available for release) or in the number of functional synapses. Changes in the amplitude of mEPSCs suggest modifications in the activity of post-synaptic AMPA receptors (channel properties and number of functional receptors).

In the present study, the amplitude of AMPAR-mediated mEPSCs was reduced by $30-36 \%\left(\mathrm{~F}_{(1,38)}=33.9, p<0.00001\right)$ in the CA1 pyramidal neurons of the hippocampus of 4- to 5-week-old prenatal ethanol-exposed animals (Figures $6 \mathrm{~b}$ and 7) compared with prenatally sucrose exposed controls of the same age (Figures 6a and 7). Prenatal ethanol exposure also decreased the mEPSCs frequency by 
$55-65 \%\left(\mathrm{~F}_{(1,28)}=25.1, p<0.0001\right) \quad($ Figures $6 \mathrm{~b}$ and 7$)$ compared with controls (Figures $6 \mathrm{a}$ and 7 ).

The miniature currents of aniracetam-treated alcoholexposed pups (Figure 6d) were similar to those of controls (Figure $6 \mathrm{c}$ ), suggesting that the nootropic drug ameliorated the reduced glutamatergic synaptic transmission induced by alcohol exposure before birth. Post-natal aniracetam treatment significantly increased the amplitude and frequency (Figure 7) of mEPSCs compared with the prenatal ethanolexposed group (amplitude: $\left.\left(\mathrm{F}_{(1,38)}=33.9\right), p<0.00001\right)$; frequency: $\left(\mathrm{F}_{(1,28)}=19.4, p<0.0002\right)$. However, there was no significant difference in the frequency of $\operatorname{mEPSCs}\left(\mathrm{F}_{(1,28)}\right.$ $=0.023, p>0.05$ ) (Figures $6 \mathrm{~d}$ and 7) of post-natal aniracetam-treated and prenatal sucrose-exposed control group compared with the prenatal sucrose-exposed control, but the factor for the interaction prenatal/post-natal treatment was significant $\left(\left(\mathrm{F}_{(1,28)}=9.2 ; p<0.005\right)\right.$.

\section{DISCUSSION}

\section{Prenatal Ethanol Effects in the Rat Model}

Physical development. Therapeutic effects of aniracetam were evaluated on a well-characterized and sensitive FASD rat model. Body weights and early developmental reflexes were taken into account as a fairly accurate index of prenatal or early post-natal development. Moderate prenatal ethanol exposure induced significant reduction in birth body weights, and their general compensation was observed by PND 5. Physical retardation and neuronal incapacity for motor control were expressed as a significant delay in development only of the righting reflex, which suggests impairment in the required motor coordination. Hannigan et al (1993) have reported that lower birthweight was a consistent characteristic of prenatal ethanol exposure, whereas other authors (Trofimov et al, 1996) did not find changes in the body mass and elementary inborn reflexes during the first 3 weeks of post-natal life, using ethanol at a dose of $5 \mathrm{~g} / \mathrm{kg} /$ day. Endocrine alterations also can impact fetal and post-natal growth and development in prenatally drug-exposed offspring. Studies have shown that prenatal alcohol or nicotine exposure can reduce post-natal plasma concentrations of insulin-like growth factor-1, a growth promoting peptide, with levels correlated with somatic and brain growth deficits in these offspring (Breese and
Leonard, 1993; Breese et al, 2000), providing biochemical evidence for specific long-term alterations related to somatic growth development.

Exploratory activities. Locomotor activity and novelty seeking behavior were assessed before administration of aniracetam. Abnormalities in horizontal and vertical activity were not evident in 18- and 25-day-old E-exposed rats when compared with sucrose-treated controls, in contrast to another report, demonstrating increased activity during the pre-weaning period (Doremus et al, 2004). In fact, 18-day-old E-treated offspring of both genders showed significantly less exploratory activity as demonstrated by novelty seeking behavior in the hole-board compared with sucrose-treated controls. Novelty seeking decrements are indicators for neophobia, anxiety, and stress disposition (Arevalo et al, 2001; Palanza et al, 2001; Vaglenova et al, 2004). Activity of all animals was mostly during the first

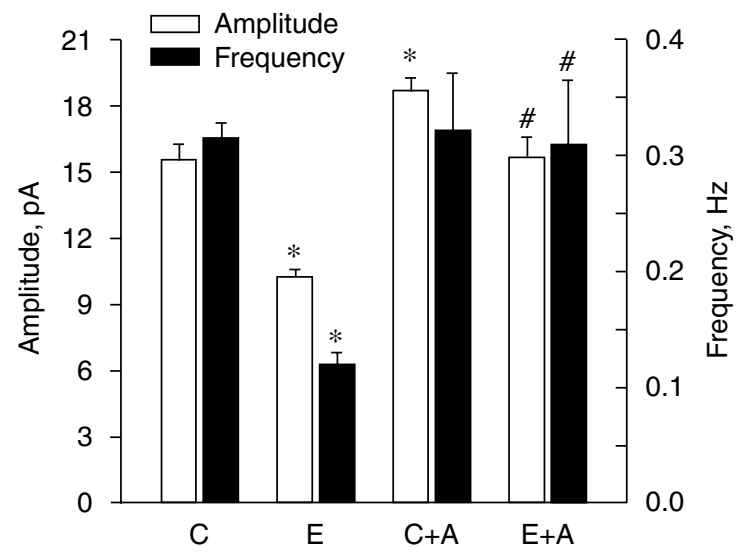

Figure 7 Effects of chronic prenatal alcohol exposure and post-natal aniracetam treatment (PND 18-27) on AMPAR-mediated synaptic transmission. Representative bar graphs illustrate the changes in mEPSCs amplitude and frequency of hippocampal CAI pyramidal neurons. Recordings were obtained at a holding potential of $-70 \mathrm{mV}$. Chronic prenatal alcohol exposure depressed the mean amplitude (pA) of mEPSCs. The mean amplitudes and frequency of mEPSCs between control and treatment groups are significantly different by two-way ANOVA $\left({ }^{*} p<0.0000 \mathrm{I}\right)$. Prenatal ethanol exposure decreased the frequency and amplitude of mEPSC. Post-natal aniracetam treatment significantly increased frequency and amplitude compared with prenatal alcohol exposure $\left({ }^{\#} p<0.000 I\right)$. Data represent mean \pm SEM. $N=9-12$.
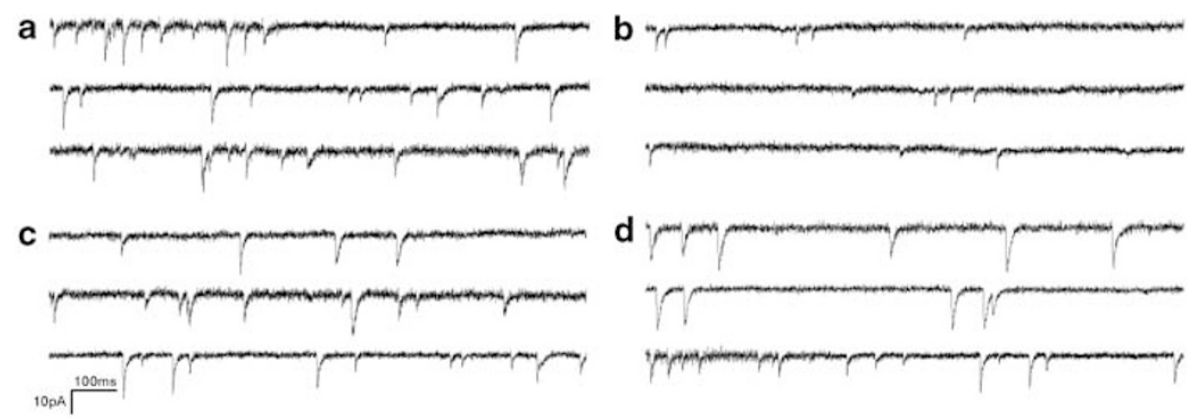

Figure 6 Post-natal aniracetam treatment (PND 18-27) enhances the depressed AMPAR-mediated synaptic transmission in hippocampal CAI region of rat offspring exposed to alcohol in utero. Sample traces of AMPAR-mediated mEPSCs illustrating that chronic prenatal alcohol exposure (b) caused a decrease in mEPSC amplitude (30-36\%) and frequency (55-65\%) compared with controls (a). Sample sweeps illustrating the effect of post-natal aniracetam in the treatment of prenatal alcohol exposure (d). At this age, aniracetam treatment significantly increased the amplitude and frequency of mEPSCs compared with controls (c). Recordings were made at a holding potential of $-65 \mathrm{mV}$, in the presence of TTX (I $\mu \mathrm{M})$, APV (50 $\mu \mathrm{M})$, and picrotoxin (50 $\mu \mathrm{M})$. 
5 min of the trial, with significant habituation to the environment expressed during the last $5 \mathrm{~min}$, which could be interpreted as adaptation to the environment. The process of habituation was apparent in both control- and ethanol-treated animals.

\section{Therapeutic Effects of Aniracetam}

Anxiolytic effects. As fear, stress, and anxiety are harbingers of cognitive problems (Ho et al, 2002; Vaglenova et al, 2004), anxiety levels were assessed specifically by measuring the number of entries onto and the length of the time spent in the open arms ('aversive area') of the plus maze. Fortyday-old rats were tested, because the adolescent is especially vulnerable to anxiety and stress (Doremus et al, 2004; Vaglenova et al, 2004). This investigation found that ethanol exposure elevated the 'anxiety state' only in female offspring. A recent study (Carneiro et al, 2005) revealed the anxiolytic effect of prenatal ethanol exposure in an earlier stage of development (21-day-old rats), whereas other authors (Day, 1997; Osborn et al, 1998) shown increased anxiety in adolescent humans and rats, possibly because brain mechanisms involved in the regulation of anxiety are immature (Doremus et al, 2004) and vulnerable to the intense hormonal alterations characteristic of this specific age.

Aniracetam administration during the preadolescent period caused strong anxiolytic effects in adolescent rats 10 days after the ending of the treatment. Interestingly, even natural levels of anxiety in control rats of both genders were overcome, and sucrose-aniracetam-treated animals showed significantly higher open-arm activity (number of entries) compared with sucrose-treated animals. Although this effect is demonstrated for the first time in a model of fetal ethanol exposure, other authors (Nakamura and Kurasawa, 2001) have reported the anxiolytic effects of aniracetam in many other models, such as the condition fear stress test, forced swim test, and submissive behavioral model (Knapp et al, 2002). These results indicate that aniracetam possesses a wide range of anxiolytic properties, which may be mediated by an interaction between the cholinergic, dopaminergic, and serotonergic systems (Nakamura and Kurasawa, 2001), and is able to reduce fetal ethanol anxiogenic effects in female offspring.

Preadolescent aniracetam treatment reversed learning and memory deficits on adult rats prenatally exposed to ethanol. This study showed the ability of aniracetam, administered during the preadolescent (PND 18-27) period, to reverse learning and memory deficits in rats exposed to a moderate dose of ethanol only prenatally. In a previous investigation (Vaglenova and Petkov, 2001), piracetam (Pyramem), aniracetam, and meclophenoxate (Centrophenoxine) showed therapeutic effectiveness on a different model with both prenatal and post-natal ethanol exposure at a dose four times lower. In the same study, aniracetam was administered to adolescent rats (PND 30-40), and learning and memory were also examined in adult rats. The effectiveness of aniracetam during two different developmental periods suggested its wide therapeutic window. Our present results demonstrated drug effects on both genders, and the recovery in females was complete, with their learning indicators (number of avoidances and number of 'good learners') outnumbering even those in the control group. Male $(\mathrm{E}+\mathrm{A})$ rats also showed restored learning and memory when compared with the ethanol-only group. A surprising result was the significantly increased number of 'helpless' and 'poor learners' in the second male control group, which received sucrose prenatally and aniracetam postnatally $(C+A)$. It is known that aniracetam, like other nootropics, does not enhance learning in healthy individuals (Gamzu et al, 1989; Vaglenova and Petkov, 2001). It could be speculated that aniracetam's positive effect on learning in female $\mathrm{E}$ animals is a result of the drug's anxiolytic effect, which helped to overcome the stress from foot shock during the trials, but that explanation is not suitable for C + A males. A higher number of 'helpless' male rats in this group was accompanied by higher number of subjects with escape failures, although escape indicators as 'mean' were not significantly different from those in the control group. Therefore, it is possible that animals classified as 'poor' or 'helpless' learners may have deficits in either general learning and memory as compared with those classified as 'good' learners, or the result may indicate significant differences in anxiety, fear, or emotional state associated with the learning task, especially in the initial stages of the task (Clausing et al, 2000; Fernandez-Teruel et al, 1991; Escorihuela et al, 1993, 1995) either condition would be observed and defined as a deficit in cognitive function. Anxiolitic drugs or physical procedures reduced anxiety and stress caused by the aversive stimulus in the two-way avoidance task (Fernandez-Teruel et al, 1991; Escorihuela et al, 1993; Savic et al, 2005). It is important to note that the anxiolitics in the mention two-way avoidance tests had been applied during the task or just before the test. Although aniracetam reduced anxiety caused by the elevated plus maze in control animals, it looked as though the drug specifically reduced the number of 'good' learners that overcame the stress and anxiety more than other subgroups. Ho et al (2002), who investigated animals with low and high indicators of anxiety by use of a two-way avoidance task, discussed these phenomena in the light of our results; anxiolitic drugs can improve avoidance behavior of 'poor performers' (ie subjects receiving high rates of shock) and disrupt the behavior of 'good performers' (subjects receiving low rates of shock). However, the validity of such an explanation in our experiments is supported only by the results obtained for male rats. It is also possible that aniracetam exhibited an 'overdose effect' only for male rats, or contributed to elevated blood corticosteroid (probably caused by the aversive stimulus used in the task) and testosterone levels. Future investigations might answer this question.

Modulatory effects of aniracetam on synaptic AMPAR function. This is the first study to demonstrate that moderate ethanol exposure on pregnant rats caused impairments in AMPAR-mediated neurotransmission in offspring. Furthermore, preadolescent aniracetam treatment ameliorated the synaptic impairments in the pups, evidenced by the similar miniature current amplitudes and frequencies in treated and control offspring.

Reduction of AMPAR-mediated mEPSC amplitude may be an effect of prenatal ethanol insult on molecules that are 
essential for post-synaptic AMPAR expression after birth. The altered frequency of mEPSC is also expected to reflect the changes in the number of pre-synaptic release sites or the probability of release. Although we cannot definitely distinguish between the two, the observed reduction in frequency further supports the idea that ethanol inhibits glutamate release in the CA1 hippocampal region (Mameli et al, 2005; Hendricson et al, 2003; Maldve et al, 2004). In addition, prenatal ethanol exposure has been shown to reduce levels of BDNF protein and mRNA levels in the hippocampus (Feng et al, 2005), which can influence AMPA and NMDA receptor-mediated synaptic transmission (Aicardi et al, 2004; Kossel et al, 2001; Kang et al, 1997; Abidin et al, 2006; Rex et al, 2006). However, at present, there are no reports available to our knowledge regarding the influence of prenatal alcohol exposure on the BDNF levels in offspring of the age group used in this study. Therefore, as suggested by Feng et al (2005), it is reasonable to presume that in utero ethanol-induced reduction of BDNF protein and mRNA expression might play a role in the decreasing amplitude and frequency of AMPAR-mediated mEPSCs.

Models for synaptic development indicate that activation of NMDA receptors in the developing brain is necessary for expression of AMPA receptors (Hanse et al, 1997). In the fetal brain, during the migration phase, which occurs before synaptogenesis, NMDA receptors play an important role in glutamate signaling (Olney et al, 2001). Thus, it is possible that some of the AMPAR-mediated synaptic dysfunctions associated with prenatal ethanol exposure are caused by an ethanol-induced disruption of glutamate signaling during this migration stage. A disruption of neuronal signaling during migration might lead neurons to migrate to ectopic locations where they will either die or form dysfunctional connections (Olney et al, 2001) in the hippocampal CA3-CA1 region as well as to the reduced glutamate release (Mameli et al, 2005; Hendricson et al, 2003; Maldve et al, 2004), thereby altering AMPARmediated neurotransmission.

The active ethanol metabolism by alcohol dehydrogenase in the CA3-CA1 area (Martinez et al, 2001) results in the accumulation of acetaldehyde (Zimatkin and Deitrich, 1995) and also in retinoic acid generation. Ethanol inhibits retinol oxidation, although the alcohol dehydrogenase pathway, thus, decreases retinoic acid levels and, consequently, impairs the adult brain function regulated by retinoic acid (Martinez et al, 2001). It makes this brain area specifically vulnerable to direct neurotoxic insult, which impairs physiological functions. Alternatively, optimal levels of neural cell adhesion molecules (eg, NCAM and L1) play an important role in stable synapse formation (Edelman and Chuong, 1982). It has been shown that perinatal ethanol exposure alters the pattern of NCAM and L1 expression, inhibiting the formation of new synapses (Minana et al, 2000; Bearer, 2001). Prenatal ethanol exposure reduces neuronal numbers (Perez et al, 1991) with less elaborate dendritic arbors, fewer dendritic spines (Smith and Davies, 1990; Abel et al, 1983; Ferrer et al, 1988; Perez et al, 1991), and decreased vesicle number per area of synaptic contact zones (Lolova et al, 1989) in the CA1 hippocampus. Therefore, the modifications in synaptic transmission observed in our study may have resulted from these morphological malformations in the CA1 area.
The nootropic compound aniracetam has been used extensively in characterizing the function of AMPARs (Isaacson and Nicoll, 1991; Tang et al, 1991; Vyklicky et al, 1991; Ghamari-Langroudi and Glavinovic, 1998). The amplitude and frequency of AMPAR-mediated mEPSCs were significantly increased in rats in the ethanolaniracetam-treated group compared with the ethanol exposed animals, and were similar to those of the controls. The increase in the amplitude and frequency contributes to the efficacy of synaptic transmission. The increase in the amplitude due to aniracetam treatment is not surprising, as aniracetam has been shown previously to increase the peak amplitude of fast excitatory synaptic transmission (Isaacson and Nicoll, 1991). Previous studies proposed that aniracetam acts as a positive modulator by slowing the rate of channel closing, desensitization (Partin et al, 1996; Suppiramaniam et al, 2001), and deactivation (Jin et al, 2005) of AMPARs. One of the new findings of this study is the increases in the frequency of AMPARmediated mEPSCs after post-natal aniracetam treatment for prenatally alcohol-exposed offspring. Explanation for mechanisms responsible for this action would be speculative at this moment. One report suggested that cellspecific post-translational factors such as phosphorylation or protein-protein interaction may be involved in regulating the ethanol sensitivity of these AMPA receptors (Woodward, 1999). Thus, it is possible that post-natal aniracetam treatment limits the chronic prenatal ethanol insult by altering the protein synthesis and post-translational modifications of the neuronal cells containing AMPA receptors.

\section{SUMMARY}

The current study was carried out using a rat model for FASD. The data demonstrated a spectrum of developmental and behavioral modifications in juvenile, adolescent, and aged animals after prenatal ethanol exposure at a moderate dose. The potential risk posed by prenatal ethanol exposure was clearly defined in both genders by changes in developmental reflexes, exploratory and novelty-seeking behavior and 'anxiety state', and by the heterogeneity of individual and group responses in learning and memory. These cognitive deficits correlated well with alterations in AMPA receptor-mediated hippocampal glutamatergic neurotransmission. It is important to note that ethanol exposure before birth resulted in dysfunction of hippocampal AMPA receptor-mediated synaptic transmission postnatally. This deficit was restored by preadolescent aniracetam treatment. Therefore, aniracetam can serve as a useful agent with wide therapeutic window.

\section{ACKNOWLEDGEMENTS}

We gratefully acknowledge $\mathrm{Dr}$ Norou Diawara at Old Dominion University, VA, for the electrophysiology statistical analysis discussion. We are grateful to Gerritt Dewitt from Digital Resource Laboratory, Auburn University, Al, USA for the figures in our paper. We are grateful to Philip Morris External Research Program for the support of the study. 


\section{DISCLOSURE/CONFLICT OF INTEREST}

The author(s) declare that, except for income received from their primary employer and funding provided by Philip Morris USA Inc. and Philip Morris External Research Program for the study, no financial support or compensation has been received from any individual or corporate entity over the past 3 years for research or professional service and there are no personal financial holdings that could be perceived as constituting a potential conflict of interest.

\section{REFERENCES}

Abel EL, Jacobson S, Sherwin BT (1983). In utero alcohol exposure: functional and structural brain damage. Neurobehav Toxicol Teratol 5: 363-366.

Abidin I, Kohler T, Weiler E, Zoidl G, Eysel UT, Lessmann V et al (2006). Reduced presynaptic efficiency of excitatory synaptic transmission impairs LTP in the visual cortex of BDNFheterozygous mice. Eur J Neurosci 24: 3519-3531.

Allan AM, Wu H, Paxton LL, Savage DD (1998). Prenatal ethanol exposure alters the modulation of the gamma-aminobutyric acidA1 receptor-gated chloride ion channel in adult rat offspring. J Pharmacol Exp Ther 284: 250-257.

Aicardi G, Argilli E, Cappello S, Santi S, Riccio M, Thoenen H et al (2004). Induction of long-term potentiation and depression is reflected by corresponding changes in secretion of endogenous brain-derived neurotrophic factor. Proc Natl Acad Sci 101: 15788-15792.

Arevalo C, de Miguel R, Hernandez-Tristan R (2001). Cannabinoid effects on anxiety- related behaviors and hypothalamic neurotransmitters. Pharmacol Biochem Behav 70: 123-131.

Barr AM, Hofmann CE, Phillips AG, Weinberg J, Honer WG (2005). Prenatal ethanol exposure in rats decreases levels of complexin proteins in the frontal cortex. Alcohol Clin Exp Res 29: $1915-1920$.

Bearer CF (2001). L1 cell adhesion molecule signal cascades: targets for ethanol developmental neurotoxicity. Neurotoxicology 22: 625-633.

Black MD (2005). Therapeutic potential of positive AMPA modulators and their relationship to AMPA receptor subunits. A review of preclinical data. Psychopharmacology (Berlin) 179: 154-163.

Bonthius DJ, West JR (1988). Blood alcohol concentration and microcephaly: a dose response study in the neonatal rat. Teratology 37: 223-231.

Breese CR, Leonard SS (1993). Long-term suppression of insulinlike growth factor-1 in rats after in utero ethanol exposure: relationship to somatic growth. J Pharmacol Exp Ther 264: 448-456.

Breese CR, Narayanan U, Birru S, Talukdar S (2000). Effect of fetal alcohol and nicotine exposure on nicotinic receptor expression. Alcohol Clin Exp Res 24: 100A.

Carneiro LM, Diogenes JP, Vasconcelos SM, Aragao GF, Noronha EC, Gomes PB (2005). Behavioral and neurochemical effects on rat offspring after prenatal exposure to ethanol. Neurotoxicol Teratol 27: 585-592.

Chudley AE, Conry J, Cook JL, Loock C, Rosales T, LeBlanc N (2005). Fetal alcohol spectrum disorder. Canadian guidelines for diagnosis. Can Med Assoc J 172(Suppl 5): S1-S21.

Clausing P, Ferguson SA, Holson RR, Allen RR, Paule MG (1995). Prenatal ethanol exposure in rats: long-lasting effects on learning. Neurotoxicol Teratol 5: 545-552.

Clausing P, Mothes HK, Opitz B (2000). Preweaning experience as a modifier of prenatal drug effects in rats and mice. Neurotoxicol Teratol 22: 113-123.
Coper H, Herrman WM (1988). Psychostimulants, analeptics, nootropics: an attempt to differentiate and assess drugs designed for the treatment of impaired brain functions. Pharmacopsychiatry 21: 211-217.

Day N (1997). Cognitive Development of the Ten-Years-Old in the Maternal Health Practices in Child Development Project. Presented at Research Society on Alcoholism Annual Scientific Meeting, San Francisco, CA, 445.

Doremus TL, Varlinskaya EI, Spear LP (2004). Age-related differences in elevated plus maze behavior between adolescent and adult rats. Ann NY Acad Sci 1021: 427-430.

Edelman GM, Chuong CM (1982). Embryonic to adult conversion of neural cell adhesion molecules in normal and staggerer mice. Proc Natl Acad Sci USA 79: 7036-7040.

Escorihuela M, Fernandez-Teruel A, Zapata A, Nunez JF, Tobena A (1993). Flumazenil prevents the anxiolytic effects of diazepam, alprazolam and adinazolam on the early acquisition of two-way active avoidance. Pharmacol Res 28: 53-58.

Escorihuela M, Tobena A, Driscoll P, Fernandez-Teruel A (1995). Effects of training, early handling, and perinatal flumazenil on shuttle box acquisition in Roman low-avoidance rats: toward overcoming a genetic deficit. Neurosci Biobehav 19: 353-367.

Feng MJ, Yan SE, Yan QS (2005). Effects of prenatal alcohol exposure on brain-derived neurotrophic factor and its receptor tyrosine kinase B in offspring. Brain Res 1042: 125-132.

Ferguson SM, Brodkin JD, Lloyd GK, Menzaghi F (2000). Antidepressant-like effects of the subtype-selective nicotinic acetylcholine receptor agonist, SIB-1508Y, in the learned helplessness rat model of depression. Psychopharmacology (Berlin) 152: 295-303.

Fernandez-Teruel A, Escorihuela RM, Boix F, Tobena A (1991). Effects of different handling-stimulation procedures and benzodiazepines on two-way active avoidance acquisition in rats. 24: 273-282.

Ferrer I, Galofre F, Lopez-Tejero D, Llobera M (1988). Morphological recovery of hippocampal pyramidal neurons in the adult rat exposed in utero to ethanol. Toxicology 48: 191-197.

Foltyn P, Lucker PW, Schnitker J, Wetzelsberger N (1983). A test model for cerebrally active drugs as demostrated by the example of the new substance aniracetam. Arzneim-Forsch/Drug Res 33: 865-867.

Gabriel KI, Glavas MM, Ellis L, Weinberg J (2005). Postnatal handling does not normalize hypothalamic corticotropin-releasing factor mRNA levels in animals prenatally exposed to ethanol. Brain Res Dev Brain Res 157: 74-82.

Gamzu ER, Hoover TM, Gracon SI, Ninteman MV (1989). Recent developments in 2-Pyrolidine-containing nootropic. Drug Dev Res 18: 177-189.

Ghamari-Langroudi M, Glavinovic MI (1998). Changes of spontaneous miniature excitatory postsynaptic currents in rat hippocampal pyramidal cells induced by aniracetam. Pflugers Arch-Eur J Physiol 435: 185-192.

Giurgea C (1980). A drug for the mind. Chem Technol 10: 360-365.

Gouliaev AH, Senning A (1994). Piracetam and other structurally related nootropics. Brain Res Dev 19: 180-222.

Hannigan JH, Cortese BM, DiCerbo JA, Radford LD (1993). Scopolamine does not differentially affect Morris maze performance in adult rats exposed prenatally to alcohol. Alcohol 10: 529-535.

Hanse E, Durand GM, Garaschuk O, Konnerth (1997). Activitydependent wiring of the developing hippocampal neuronal circuit. Semin Cell Dev Biol 8: 35-42.

Heise GA (1984). Behavioral methods for measuring effects of drugs on learning and memory in animals. Med Res Rev 4: 535-558.

Hendricson AW, Thomas MP, Lippmann MJ, Morrisett RA (2003). Suppression of L-type voltage-gated calcium channel-dependent synaptic plasticity by ethanol: analysis of miniature synaptic 
currents and dendritic calcium transients. J Pharmacol Exp Ther 307: $550-558$.

Ho YJ, Eichendorff J, Schwarting RK (2002). Individual response profiles of male Wistar rats in animal models for anxiety and depression. Behav Brain Res 136: 1-12.

Hoyme HE, May PA, Kalberg WO, Kodituwakku P, Gossage JP, Trujillo PM et al (2005). A practical clinical approach to diagnosis of Fetal Alcohol Spectrum Disorders. Clarification of the 1996 Institute of Medicine criteria. Pediatrics 115: 39-47.

Hsia AY, Malenka RC, Nicoll RA (1998). Development of excitatory circuitry in the hippocampus. J Neurophysiol 79: 2013-2024.

Ito I, Tanabe S, Kohda A, Sugiyama H (1990). Allosteric potentiation of quisqualate receptors by a nootropic drug aniracetam. J Physiol 424: 533-543.

Irvine LF (2003). Relevance of the developmental toxicity of ethanol in the occupational setting. J Appl Toxicol 23: 289-299.

Isaacson JS, Nicoll RA (1991). Aniracetam reduces glutamate receptor desensitization and slows the decay of fast excitatory synaptic currents in the hippocampus. Proc Natl Acad Sci USA 88: $10936-10940$.

Jin R, Clark S, Weeks AM, Dudman JT, Gouaux E, Partin KM (2005). Mechanism of positive allosteric modulators acting on AMPA receptors. J Neurosci 25: 9027-9036.

Jones KL, Smith DW, Ulleland CN, Streissguth P (1973). Pattern of malformation in offspring of chronic alcoholic mothers. Lancet 1: 1267-1271.

Keshavarzian A, Choudhary S, Holmes EW, Yong S, Banan A, Jakate $S$ et al (2001). Preventing gut leakiness by oats supplementation ameliorates alcohol - induced liver damage in rats. Pharmacol Exp Ther 299: 442-448.

Kang H, Welcher AA, Shelton D, Schuman EM (1997). Neurotrophins and time: different roles for TrkB signaling in hippocampal long-term potentiation. Neuron 19: 653-664.

Kim CK, Kalynchuk LE, Kornecook TJ, Mumby DG, Dadgar NA, Pinel JP et al (1997). Object-recognition and spatial learning and memory in rats prenatally exposed to ethanol. Behav Neurosci 111: 985-995.

Knapp RJ, Goldenberg R, Shuck C, Cecil A, Watkins J, Miller C et al (2002). Antidepressant activity of memory-enhancing drugs in the reduction of submissive behavior model. Eur J Pharmacol 440: 27-35.

Kossel AH, Cambridge SB, Wagner U, Bonhoeffer T (2001). A caged $\mathrm{Ab}$ reveals an immediate/instructive effect of BDNF during hippocampal synaptic potentiation. Proc Natl Acad Sci USA 98: 14702-14707.

Lolova I, Lolov V, Petkov VV, Vaglenova J (1989). Changes in the synapses of rat hippocampus following pre- and postnatal alcohol exposure. Anat Anz 169: 285-294.

Maier SE, West JR (2001). Drinking patterns and alcohol-related birth defects. Alcohol Res Health 25: 168-174.

Maldve RE, Chen X, Zhang TA, Morrisett RA (2004). Ethanol selectively inhibits enhanced vesicular release at excitatory synapses: real-time visualization in intact hippocampal slices. Alcohol Clin Exp Res 28: 143-152.

Mameli M, Zamudio PA, Carta M, Valenzuela CF (2005). Developmentally regulated actions of alcohol on hippocampal glutamatergic transmission. J Neurosci 25: 8027-8036.

Martinez SE, Vaglenova J, Sabria J, Martinez CM, Farres J, Pares X (2001). Distribution of alcohol dehydrogenase mRNA in the rat central nervous system. Consequences of brain ethanol and retinoid metabolism. Eur J Biochem 268: 5045-5056.

Matthews DB, Simson PE (1998). Prenatal exposure to ethanol disrupts spatial memory: effect of the training-testing delay period. Physiol Behav 64: 63-67.

Minana R, Climent E, Barettino D, Segui JM, Renau-Piqueras J, Guerri C (2000). Alcohol exposure alters the expression pattern of neural cell adhesion molecules during brain development. J Neurochem 75: 954-964.
Morris RG (1989). Synaptic plasticity and learning: selective impairment of learning rats and blockade of long-term potentiation in vivo by the $N$-methyl-D-aspartate receptor antagonist AP5. J Neurosci 9: 3040-3057.

Morris RG, Anderson E, Lynch GS, Baudry M (1986). Selective impairment of learning and blockade of long-term potentiation by an $N$-methyl-D-aspartate receptor antagonist, AP5. Nature 319: $774-776$.

Nakamura K, Kurasawa M (2001). Anxiolytic effects of aniracetam in three different mouse models of anxiety and the underlying mechanism. Eur J Pharmacol 420: 33-43.

Neese S, La Grange L, Trujillo E, Romero D (2004). The effects of ethanol and silymarin treatment during gestation on spatial working memory. BMC Complement Altern Med 4: 4.

Olney JW (2002). New insights and new issues in developmental neurotoxicology. Neurotoxicology 23: 659-668.

Olney JW (2004). Fetal alcohol syndrome at the cellular level. Addict Biol 9: 137-149.

Olney JW, Wozniak DF, Jevtovic-Todorovic V, Ikonomidou C (2001). Glutamate signaling and the fetal alcohol syndrome. Ment Retard Dev Disabil Res Rev 7: 267-275.

O'Malley KD, Nanson J (2002). Clinical implications of a link between Fetal alcohol Spectrum Disorder and attention-deficit hyperactivity disorder. Can J Psychiatry 47: 349-354.

Osborn JA, Kim CK, Steiger J, Weinberg J (1998). Prenatal ethanol exposure differentially alters behavior in males and females on the elevated plus maze. Alcohol Clin Exp Res 22: 685-696.

Palanza P, Morley-Fletcher S, Laviola G (2001). Novelty seeking in periadolescent mice: sex differences and influence of intrauterine position. Physiol Behav 72: 255-262.

Partin KM, Fleck MW, Mayer ML (1996). AMPA receptor flip/flop mutants affecting deactivation, desensitization, and modulation by cyclothiazide, aniracetam, and thiocyanate. J Neurosci 16 : 6634-6647.

Petkov VD, Konstantinova E, Petkov VV, Vaglenova J (1991). Learning and memory in rats exposed pre- and postnataly to alcohol. An attempt at pharmacolocical control. Meth Find Exp Clin Pharmacol 13: 43-50.

Perez HD, Villanueva JE, Salas JM (1991). Behavioral and hippocampal morphological changes induced by ethanol administered to pregnant rats. Ann NY Acad Sci 625: 300-304.

Reisel D, Bannerman DM, Schmitt WB, Deacon RM, Flint J, Borchardt $\mathrm{T}$ et al (2002). Spatial memory dissociations in mice lacking GluR1. Nat Neurosci 9: 868-873.

Riley EP, Mattson SN, Li TK, Jacobson SW, Coles CD, Kodituwakku PW et al (2003). Neurobehavioral consequences of prenatal alcohol exposure. Alcohol Clin Exp Res 26: 1863-1871.

Riley EP, Thomas JD, Goodlett CR, Klintsova AY, Greenough WT, Hungund BL et al (2001). Fetal alcohol effects: mechanisms and treatment. Alcohol Clin Exp Res 25: 110S-116S.

Rex CS, Lauterborn JC, Lin CY, Kramar EA, Rogers GA, Gall CM et al (2006). Restoration of long-term potentiation in middleaged hippocampus after induction of brain-derived neurotrophic factor. J Neurophysiol 96: 677-685.

Savic MM, Obradovic DI, Ugresic ND, Cook JM, Sarma PV, Bokonjic DR (2005). Bidirectional effects of benzodiazepine binding site ligands on active avoidance acquisition and retention: differential antagonism by flumazenil and beta-CCt. Psychopharmacology (Berlin) 180: 455-465.

Shorvon S (2001). Pirrolidone derivates. Lancet 358: 1885-1892.

Smith DE, Davies DL (1990). Effect of perinatal administration of ethanol on the CA1 pyramidal cell of the hippocampus and Purkinje cell of the cerebellum: an ultrastructural survey. J Neurocytol 19: 708-717.

Snyder J, Nanson J, Snyder RE, Block GW (1997). Stimulant efficacy in children with FAS. In: Strissguth A, Kanter J (eds). 
The Challenge of Fetal Alcohol Syndrome; Overcoming Secondary Disabilities. University of Washington Press: Seattle. pp 64-77.

Sokol RJ, Delaney-Black V, Nordstrom B (2003). Fetal alcohol spectrum disorder. JAMA 290: 2996-2999.

Spear LP (2000). The adolescent brain and age-related behavioral manifestations. Neurosci Behav Rev 24: 417-463.

Spong CY, Abebe DT, Gozes I, Brenneman DE, Hill JM (2001). Prevention of fetal demise and growth restriction in a mouse model of Fetal Alcohol Syndrome. JPET 297: 774.

Suppiramaniam V, Bahr BA, Sinnarajah S, Owens K, Rogers G, Yilma $S$ et al (2001). Member of the Ampakine class of memory enhancers prolongs the single channel open time of reconstituted AMPA receptors. Synapse 40: 154-158.

Tang CM, Shi QY, Katchman A, Lynch G (1991). Modulation of the time course of fast EPSCs and glutamate channel kinetics by aniracetam. Science 254: 288-290.

Thomas JD, La Fiette MH, Quinn VR, Riley EP (2000). Neonatal choline supplementation ameliorates the effects of prenatal alcohol exposure on a discrimination learning task in rats. Neurotoxicol Teratol 22: 703-711.

Trofimov SS, Ostrovskaia RU, Smol'nikova NM, Nemova EP, Voronina TA (1996). The significance of perinatal alcoholization and its withdrawal in the development of late cognitive disorders in rats. Eksp Klin Farmakol 59: 44-46.

Vaglenova J (1992). Fetal Alcohol Syndrome in rats and correction with nootropic drugs. PhD Thesis, Sofia, Bulgaria. pp 171.

Vaglenova J, Birru S, Pandiella NM, Breese CR (2004). An assessment of the long-term developmental and behavioral teratogenicity of prenatal nicotine exposure. Behav Brain Res 150: $159-170$.

Vaglenova J, Petkov VV (1998). Fetal Alcohol Effects in rats exposed pre- and postnatally to a low dose of ethanol. Alcohol Clin Exp Res 22: 697-703.

Vaglenova J, Petkov VV (2001). Can nootropic drugs be effective against the impact of ethanol teratogenicity on cognitive performance? Eur Neuropsychopharm 11: 33-40.
Voronina TA (1989). Pharmacology of Nootropics (Experimental and clinical studies). Nauka: Moscow, Russia.

Vyklicky Jr L, Patneau DK, Mayer ML (1991). Modulation of excitatory synaptic transmission by drugs that reduce desensitization at AMPA/kainate receptors. Neuron 7: 971-984.

Wainwright PE (1998). Issues of design and analysis relating to the use of multiparous species in developmental nutritional studies. J Nutr 128: 661-663.

Weeber EJ, Savage DD, Sutherland RJ, Caldwell KK (2001). Fear conditioning-induced alterations of phospholipase C-betala protein level and enzyme activity in rat hippocampal formation and medial frontal cortex. Neurobiol Learn Mem 76: 151-182.

Woodward JJ (1999). Ionotropic glutamate receptors as sites of action for ethanol in the brain. Neurochem Int 35: 107-113.

Yonkov D, Georgiev V, Kambourova T (1989). Further evidence for the GABAergic influence on memory. Interaction of GABAergic transmission with angiotensin II on memory processes. Methods Find Exp Clin Pharmacol 11: 603-606.

Yoshihara T, Ichitani Y (2004). Hippocampal N-methyl-D-aspartatereceptor-mediated encoding and retrieval processes in spatial working memory: delay-interposed radial maze performance in rats. Neuroscience 129: 1-10.

Zeng XJ, Tietz EI (1999). Benzodiazepine tolerance at GABAergic synapses on hippocampal CA1 pyramidal cells. Synapse 31: 263-277.

Zimatkin SM, Deitrich RA (1995). Aldehyde dehydrogenase activities in the brains of rats and mice genetically selected for different sensitivity to alcohol. Alcohol Clin Exp Res 19: 13001306.

Zimmerberg B, Weston HE (2002). Postnatal stress of early weaning exacerbates behavioral outcome in prenatal alcoholexposed juvenile rats. Pharmacol Biochem Behav 73: 45-52.

Zola-Morgan S, Squire LR (1986). Memory impairment in monkeys following lesions limited to the hippocampus. Behav Neurosci 100: 155-160. 